\title{
DADOS ISOTÓPICOS Pb-Pb EM ZIRCÃO (EVAPORAÇÃO) E Sm-Nd DO COMPLEXO GRANÍTICO ESTRELA, PROVÍNCIA MINERAL DE CARAJÁS, BRASIL: IMPLICAÇÕES PETROLÓGICAS E TECTÔNICAS
}

\section{CARLOS EDUARDO DE MESQUITA BARROS ${ }^{1,4}$, MOACIR JOSÉ BUENANO MACAMBIRA ${ }^{1,3}$, PIERRE BARBEY ${ }^{2} \&$ THOMAS SCHELLER ${ }^{1,3}$}

\begin{abstract}
PB-PB EVAPORATION ON ZIRCON AND SM-ND DATA OF THE ESTRELA GRANITE COMPLEX, CARAJÁS METALOGENIC PROVINCE, BRAZIL: PETROLOGIC AND TECTONIC IMPLICATIONS The Estrela Granite Complex is a syntectonic alkaline (A-type) massif located to the east of the Carajás range, southeastern of the Amazonian Craton. $\mathrm{Pb}-\mathrm{Pb}$ evaporation zircon analysis yielded an age of $2763 \pm 7 \mathrm{Ma}$ to its emplacement. The petrogenetic model considering the partial melting of dehydrated crustal sources (enderbites) is favoured by the Sm-Nd model ages ( $\left.\mathrm{T}_{\mathrm{DM}}\right)(2.97 \mathrm{Ga}$ to $3.19 \mathrm{Ga})$ and the negative $\varepsilon_{\mathrm{Nu}(0)}$ values $(-0.38$ to -2.06$)$. The low initial ${ }^{87} \mathrm{Sr} /{ }^{86} \mathrm{Sr}$ ratios could suggest the partial melting of Rb-depleted granulitic rocks. The short time interval between the Estrela Granite Complex and the mafic-ultramafic (Luanga Complex) and Planalto and Plaquê granites shows that a widespread magmatic event took place at 2.76 b.y. ago in the northern part of the Carajás Metalogenic Province as well as permit to date the age of an important event of shortening. The following sequence of events is proposed: a) development of the former crust ( $3.2 \mathrm{Ga}$ to 3.0 ); b) development of the gneissic basement ( $2.97 \mathrm{Ga}$ to $2.81 \mathrm{Ga}$ ); c) distensive regime, Carajás basin formation and metavolcano-sedimetary deposition (between $2.81 \mathrm{Ga}$ and $2.76 \mathrm{Ga}$ ); d) syntectonic granite emplacement and high-temperature/lowpressure metamorphism during weak protracted shortenning ( 2.76 to $2.74 \mathrm{Ga}$ ).
\end{abstract}

Keywords: $\mathrm{Pb}-\mathrm{Pb}$ on zircon; Sm-Nd; Archean, Estrela; syntectonic granites; Carajás Metalogenic Province.

Resumo O Complexo Granítico Estrela é um maciço sintectônico de assinatura geoquímica comparável àquela dos granitos do tipo A. A idade de $2763 \pm 7 \mathrm{Ma}$, obtida pelo método de evaporação de zircão, marca a idade de colocação deste maciço e permite precisar com mais segurança a idade de um evento compressivo na evolução tectono-metamórfica arqueana da Província Mineral de Carajás. Análises Sm-Nd em rocha total forneceram valores de $\varepsilon_{N d}$ entre $-0,38$ e $-2,06$ que, para idades de cristalização de 2763 Ma, corresponderiam a fontes crustais com idades-modelo $\mathrm{Sm}-\mathrm{Nd}\left(\mathrm{T}_{\mathrm{DM}}\right)$ de $2,97 \mathrm{Ga}$ a $3,19 \mathrm{Ga}$. As baixas razões iniciais ${ }^{87} \mathrm{Sr} /{ }^{86} \mathrm{Sr}$ indicam fontes crustais empobrecidas em Rb, muito provavelmente de natureza granulítica (enderbitos). A semelhança das idades do Complexo Granítico Estrela com as idades das rochas máficas/ultramáficas do Complexo Luanga e dos granitos Planalto e Plaquê colocam em evidência um amplo magmatismo ocorrido a 2,76 Ga na parte norte da Província Mineral de Carajás. Uma sequeência de eventos é proposta: a) formação de crosta continental ( 3,2 a 3,0 Ga); b) formação de embasamento gnáissico (2,97 a 2,81 Ga); c) formação e preenchimento da Bacia Carajás em regime distensivo e estágio proto-oceano (entre 2,81 e 2,76 Ga); d) colocação de granitos sintectônicos e metamorfismo de alta temperatura e baixa pressão durante fraca e prolongada fase de compressão. $(2,76$ a $2,74 \mathrm{Ga})$.

Palavras-chave: $\mathrm{Pb}-\mathrm{Pb}$ em zircão; Sm-Nd; Arqueano; Estrela; granitos sintectônicos; Província Mineral de Carajás.

INTRODUÇÃO O estudo das relações entre plutonismo, metamorfismo e deformação, discutidas por muitos autores (Delor et al. 1991, Bloem et al. 1991, Jelsma et al. 1993), tem contribuído para a compreensão da evolução tectono-termal de terrenos de diferentes idades. Os granitos sintectônicos são marcadores de fases de deformação, daí a importância de sua caracterização e da determinação de suas idades, dentro de uma óptica integrada que envolve as petrologias ígnea e metamórfica, a geologia estrutural e a geocronologia.

Na última década, a importância do papel dos granitos neoarqueanos na evolução tectono-termal na Província Mineral de Carajás foi reconhecida por diversos autores (Lindenmayer et al. 1994, Huhn et al. 1999, Barros et al. 2001). Este novo enfoque levou Barros et al. (2001) a sugerir a presença de um cinturão plutono-metamórfico delineado pela coalescência de auréolas tectono-metamórficas presentes nas séries metavulcanosedimentares do Supergrupo Itacaiúnas ao redor de corpos granitóides sintectônicos.

A similaridade entre a idade do Complexo Granítico Estrela e as idades de associações máficas/ultramáficas acamadadas que ocorrem na região de Carajás (p.ex. Complexo Luanga) traz algumas complicações quando são considerados os regimes tectônicos esperados durante a colocação dos magmas máficos/ultramáficos com os esforços compressivos que aturaram durante a colocação destes granitos neoarqueanos na região de Carajás. Neste trabalho são apresentados os dados geocronológicos $\mathrm{Pb}-\mathrm{Pb}$ em zircão (evaporação) e Sm-Nd (rocha total) do Complexo Granítico Estrela e são discutidas as implicações petrológicas e tectônicas deste

\footnotetext{
1 - Depto. de Geoquímica e Petrologia (Universidade Federal do Pará). Campus Universitário do Guamá. CP 1611, Belém - PA, CEP 66075-100.E-mails: cadu@ufpa.br, moamac@ufpa.br, scheller@ufpa.br

2 - Université Henri Poincaré - Nancy I e Centre de Recherches Pétrographiques et Géochimiques (CRPG - CNRS).E-mail: barbey@crpg.cnrs-nancy.fr

3 - Laboratório de Geologia Isotópica (Pará-Iso) do Centro de Geociências da UFPA.

4 - Grupo de Pesquisa Petrologia de Granitóides, Bolsista do CNPq.
} 
magmatismo na geologia da região de Carajás.

GEOLOGIA REGIONAL A região de Carajás (Fig. 1a), localizada na parte sudeste do Cráton Amazônico, é constituída em grande parte de rochas arqueanas (Tabela 1). A importância econômica desta província é incontestável pela grande quantidade de depósitos minerais (Docegeo 1988). A Província Mineral de Carajás tem sido dividida em dois domínios com base em dados litológicos e geocronológicos (Docegeo 1988, Costa et al. 1990, Macambira \& Lafon 1995, Dall'Agnol et al. 1997). O domínio meridional corresponde ao Terreno Granito-Greenstone de Rio Maria, cujas rochas têm idades de 2,97 a 2,87 Ga, sendo por isto mais antigas do que o Domínio Carajás, que compreende a Serra do Carajás e seu entorno, onde predominam rochas com $2,76 \mathrm{Ga}$. As principais unidades litoestratigráficas desta região são apresentadas a seguir.

Terreno granito-greenstone de Rio Maria Este domínio ocupa a parte meridional da Província Mineral de Carajás, cujo limite norte não foi precisamente definido, mas provavelmente se situe a sul do município de Canaã dos Carajás. O limite sul deste terreno se localiza no norte do Estado do Mato Grosso.

As seqüências do tipo greenstone de Rio Maria (Supergrupo Andorinhas) são constituídas de metabasaltos, intercalações de talco xistos, metatufos, metacherts e de formações ferríferas (Grupo Babaçu) e metapelitos, metapsamitos e meta-riodacitos (Grupo Lagoa Seca) (Docegeo 1988). Datações (U-Pb em zircão) de rochas vulcânicas félsicas do Grupo Lagoa Seca apontam idades de $2904 \pm 22$ Ma e $2971 \pm 5$ Ma (Macambira \& Lafon 1995).

Dentre os granitóides da região de Rio Maria se destacam o Tonalito Arco Verde, o Granito Guarantã, o Granodiorito Rio Maria, o Tonalito Parazônia, o Trondhjemito Mogno e os granitos Xinguara e Mata Surrão(Dall'Agnol et al. 1997). As idades destas rochas variam de 2,96 Ga a 2,87 Ga (Macambira \& Lafon 1995).

Domínio Carajás O Domínio Carajás se situa no norte da Província Mineral de Carajás e engloba a Serra de Carajás e o seu entorno. Este domínio é limitado a norte por rochas granitóides sintectônicas do Cinturão Maroni-Itacaiúnas (Macambira et al. 2003), porém a localização exata do limite ainda não foi estabelecida. A unidade mais antiga do Domínio Carajás é o Complexo Pium

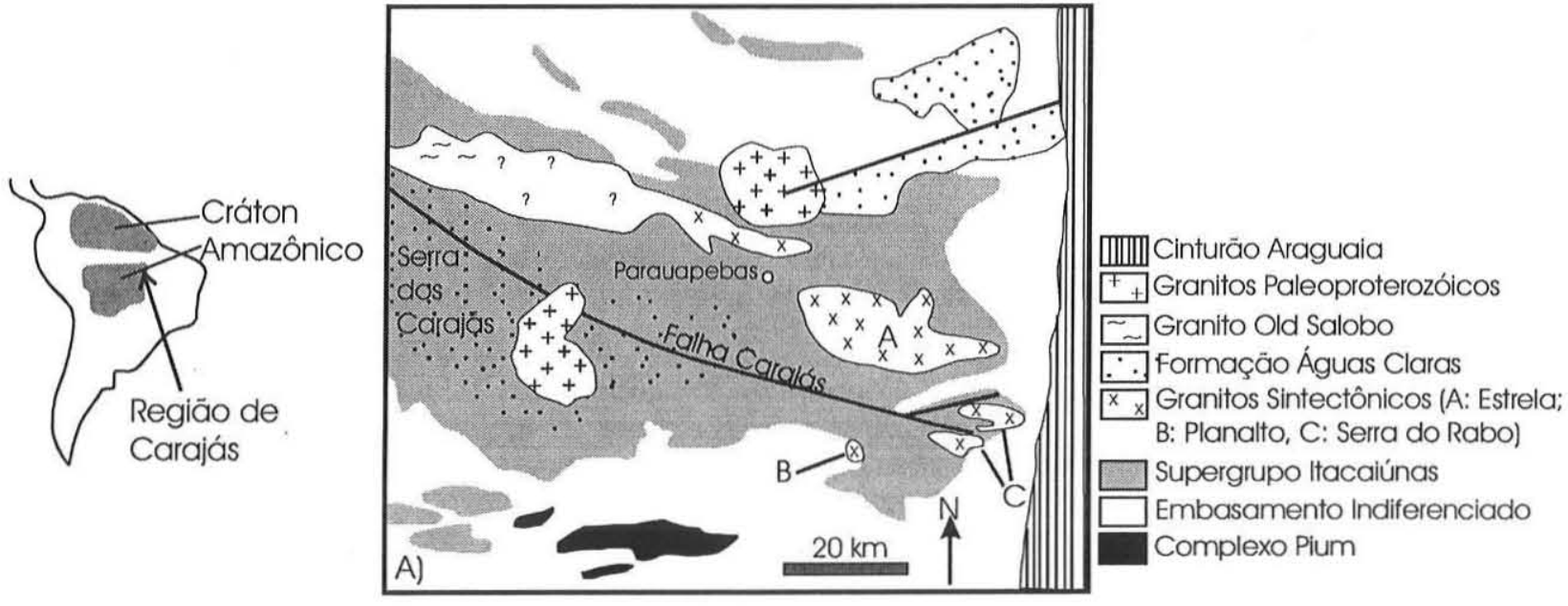

Complexo Granítico Estrela Formaçōes Ferríferas Bandadas Metabásicas, xistos ultramáficos e metapelitos

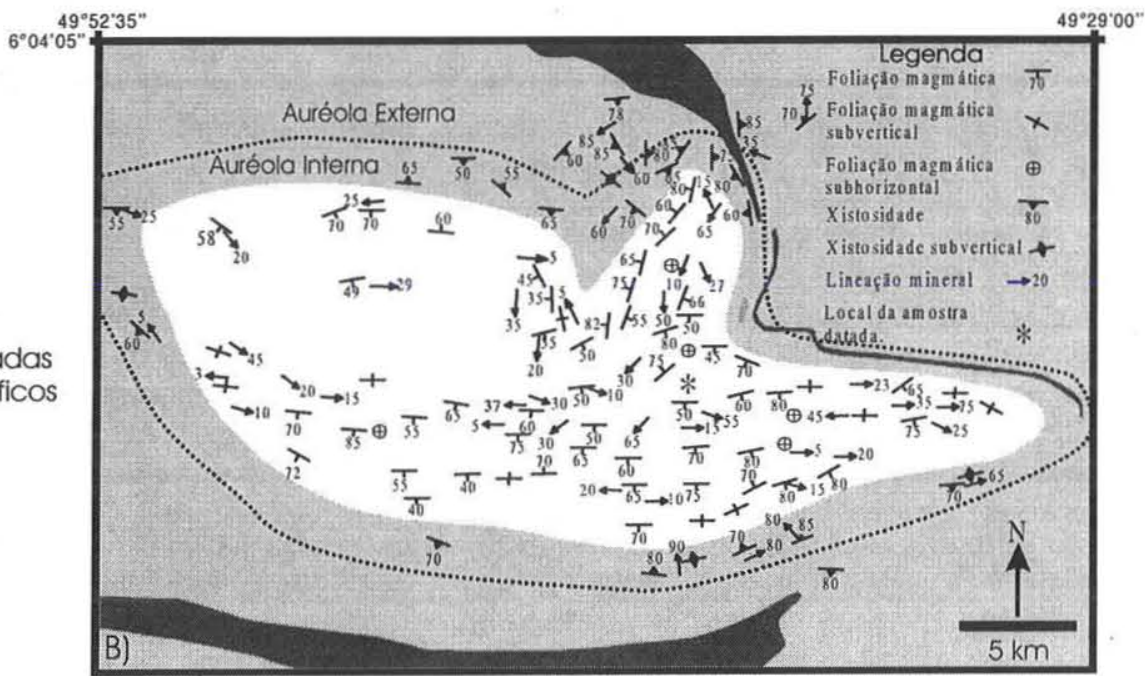

Figura I- a) Mapa de localização da área estudada. b) Mapa geológico esquemático da parte norte da Província Mineral de Carajás, modificado de Docegeo (1988) e Barros et al. (1997). b) Mapa geológico simplificado do Complexo Granítico Estrela (modificado de Barros et al. 2001). 
Tabela I- Síntese dos dados geocronológicos da parte norte da Província Mineral de Carajás (modificado de Macambira \& Lafon 1995).

\begin{tabular}{|c|c|c|c|c|}
\hline Unidade & Rocha & Idade & Método & Referências \\
\hline $\begin{array}{l}\text { Granitos } \\
\text { Paleoproterozóicos }\end{array}$ & $\begin{array}{l}\text { Granitos pós-tectônicos, } \\
\text { alcalinos, metaluminosos }\end{array}$ & $1874 \pm 2 \mathrm{Ma}$ & U-Pb, zircão & Machado et al. 1991 \\
\hline $\begin{array}{l}\text { Granito Old Salobo } \\
\text { Granitos do Rio Itacaiúnas }\end{array}$ & $\begin{array}{l}\text { Granitos alcalinos e } \\
\text { metaluminosos }\end{array}$ & $\begin{array}{c}2573 \pm 3 \mathrm{Ma} \\
2560 \pm \mathrm{Ma}\end{array}$ & $\begin{array}{l}\text { U-Pb, zircão } \\
\text { Evap. zircão }\end{array}$ & $\begin{array}{l}\text { Machado et al. } 1991 \\
\text { Souza et al. } 1996\end{array}$ \\
\hline Diques Máficos & Metagabros & $2708 \pm 37 \mathrm{Ma}$ & $\begin{array}{l}\text { Evaporação } \\
\text { zircão }\end{array}$ & Mougeot et al. 1996 \\
\hline $\begin{array}{l}\text { Granitos Planalto, Plaquê } \\
\text { e Serra do Rabo }\end{array}$ & $\begin{array}{l}\text { Granitos alcalinos e } \\
\text { metaluminosos }\end{array}$ & $\begin{array}{c}2747 \pm 2 \mathrm{Ma} \\
2727 \pm 29 \mathrm{Ma}\end{array}$ & $\begin{array}{l}\text { Evaporação } \\
\text { zircão }\end{array}$ & $\begin{array}{l}\text { Huhn et al. 1999, Avelar } \\
\text { 1996, Sardinha et al. } 2001 .\end{array}$ \\
\hline Complexo Luanga & Máficas e ultramáficas & $2763 \pm 6 \mathrm{Ma}$ & U-Pb ,zircão & Machado et al. 1991 \\
\hline Supergrupo Itacaiúnas & Anfibolitos & $2761 \pm 3 \mathrm{Ma}$ & U-Pb, zircão & Machado et al. 1991 \\
\hline Complexo Xingu & $\begin{array}{l}\text { Gnaisses e granitóides } \\
\text { deformados }\end{array}$ & $2851 \pm 4 \mathrm{Ma}$ & U-Pb, zircão & Machado et al. 1991 \\
\hline Complexo Pium & $\begin{array}{l}\text { Granulitos: metamorf. } \\
\text { cristalização }\end{array}$ & $\begin{array}{c}2859 \pm 9 \mathrm{Ma} \\
3002 \pm 14 \mathrm{Ma}\end{array}$ & U-Pb, zircão & Pidgeon et al. 2000 \\
\hline
\end{tabular}

(Fig. 1a), o qual se situa a sul da Serra dos Carajás e compreende granulitos máficos e enderbitos que ocorrem em corpos alongados na direção E-W (Docegeo 1988). As idades (U-Pb em zircão) de $3002 \pm 14 \mathrm{Ma}$ e $2859 \pm 9 \mathrm{Ma}$ foram interpretadas como a idade de cristalização dos protólitos e de granulitização, respectivamente (Pidgeon et al. 2000). Renne et al. (1988) obtiveram idades ${ }^{40} \mathrm{Ar} /$ ${ }^{39} \mathrm{Ar}$ de 2,5 e 2,7 Ga em anfibólios, as quais foram interpretadas como datando diferentes fases de aquecimento. Idades em torno de 2,5 Ga têm sido amplamente obtidas em rochas da região de Carajás, como resultado, sobretudo, da reabertura dos sistemas isotópicos Rb-Sr (Macambira \& Lafon 1995).

Granitóides fortemente deformados, atribuídos ao Complexo Xingu, afloram próximo ao alvo Salobo, sob a denominação de Gnaisse Cascata, e na pedreira CIMCOP ( $\mathrm{km} 16$ da PA 275). A idade (U-Pb em zircão) deste último é de $2851 \pm 4 \mathrm{Ma}$ (Machado $e t$ al. 1991).

O Supergrupo Itacaiúnas (Fig. 1a) engloba rochas metavulcano-sedimentares pertencentes aos grupos Salobo, Pojuca, Grão Pará e Buritirama (Docegeo 1988). O Grupo Grão Pará é formado por vulcânicas máficas intercaladas com formações ferríferas da Formação Carajás (Docegeo 1988). Lindenmayer \& Fyfe (1991) propuseram que as rochas dos grupos Salobo e Pojuca seriam variações laterais do Grupo Grão Pará, submetidas a metamorfismo de fácies piroxênio hornfels. Datações (U-Pb em zircão) de rochas metabasaltos dos grupos Salobo e Pojuca (Machado et al. 1991) indicaram idades de $2761 \pm 3 \mathrm{Ma}$.

Rochas máficas acamadadas, localizadas nas proximidades da Serra Pelada e denominadas de Complexo Luanga (Docegeo 1988), apresentaram idades (U-Pb em zircão) de $2763 \pm 6 \mathrm{Ma}$ (Machado $e t$ al. 1991). Segundo esses autores, as rochas do Complexo Luanga cortam as rochas supracrustais do Supergrupo Itacaiúnas.

No Domínio Carajás afloram granitos alongados na direção EW, de caráter sintectônico a tardi-tectônico de tendência alcalina e metaluminosa, representados pelos granitos Estrela, Planalto, Plaquê, (Fig. la) e Serra do Rabo. Datações Pb-Pb em zircão (evaporação) (Macambira et al. 1996, Huhn et al. 1999) e U-Pb em zircão (Sardinha et al. 2001) forneceram idades de 2727 $\pm 29 \mathrm{Ma} \mathrm{a} 2743 \pm$ 1,6 Ma para os três últimos corpos.

Na Serra dos Carajás, aflora a Formação Águas Claras (Fig. 1a), que engloba extensas exposições de arenitos e silititos de ambientes litorâneo a fluvial (Nogueira et al. 1995). Estas rochas são cortadas por diques e soleiras de diabásio/gabro, cujas datações U-Pb em zircão (Mougeot et al. 1996) apontaram idades de $2708 \pm 37 \mathrm{Ma}$.

O Granito Old Salobo (2573 \pm 3 Ma, U-Pb zircão; Machado et al. 1991) aflora a sul do alvo Salobo, mostra sinais de deformação e assinatura moderadamente alcalina (Lindenmayer et al. 1994). Uma idade semelhante (Pb-Pb em rocha total), de $2525 \pm 38 \mathrm{Ma}$, foi obtida para granitos foliados da região do Rio Itacaiúnas (Souza et al. 1996).

Em ambos domínios afloram diversos granitos paleoproterozóicos (Fig. la) que são discordantes da estruturação regional, e formados por rochas isotrópicas, alcalinas e metaluminosas com quimismo comparável ao dos granitos do tipo A (Docegeo 1988; Dall'Agnol et al. 1997). A idade (U-Pb em zircão) destas rochas é de $1,88 \mathrm{Ga}$ (Machado et al. 1991).

OCOMPLEXO GRANÍTICOESTRELA Estemaciçogranítico, situado a leste da Serra dos Carajás (Figs. 1a e 1b), é constituído de três principais plútons monzograníticos, os quais têm ampla variação faciológica marcada pela abundância relativa de clinopiroxênio, hornblenda e biotita. Estas rochas têm altas razões $\mathrm{Fe} /(\mathrm{Fe}+\mathrm{Mg})$, elevados teores de $\mathrm{Zr}$ (146-632 ppm), Y (13-404 ppm), $\mathrm{Nb}(21-45 \mathrm{ppm})$ e elementos terras raras, exceto $\mathrm{Eu}$, o que resulta em uma assinatura alcalina e metaluminosa (Barros et al. 1997), semelhante àquela dos granitos do tipo A de Whalen et al. (1987).

Os dados geocronológicos, disponíveis para estas rochas, limitavam-se a uma idade de $2527 \pm 34$ Ma obtida pelo método RbSr em rocha total (Barros et al. 1992). Naquela ocasião se obteve a razão inicial ${ }^{87} \mathrm{Sr} /{ }^{86} \mathrm{Sr}=0,7018 \pm 0,0020$, cujo baixo valor será discutido mais adiante.

A evolução estrutural deste maciço granítico é marcada por bandamentos magmáticos $\left(\mathrm{S}_{0}\right)$ subverticais nas bordas do corpo e subhorizontais no centro dos plútons. Uma xistosidade $\left(\mathrm{S}_{1}\right)$ subvertical, de direção E-W e zonas miloníticas concordantes permite dizer que sua colocação ocorreu concomitantemente a esforços compressivos. Durante a intrusão do magma quente, os esforços de expansão lateral, juntamente aos esforços regionais criaram nas suas rochas encaixantes uma auréola termal interna e uma auréola termal externa (Fig. 1b) relativamente mais fria (Barros et 
al. 2001).

RESULTADOS As datações $\mathrm{Pb}-\mathrm{Pb}$ em zircão (evaporação) e SmNd (rocha total) foram realizadas no espectrômetro Finnigan Mat 262 do Laboratório de Geologia Isotópica (Pará-Iso) da Universidade Federal do Pará.

Geocronologia Pb-Pb em zircão CONDIÇÕESANALÍTICAS A amostra do Complexo Granítico Estrela escolhida para datação pelo método $\mathrm{Pb}-\mathrm{Pb}$ em zircão (evaporação) corresponde a um hornblenda sienogranito ( $\mathrm{CRN}-8)$ coletado na parte centro-leste do complexo granítico (648929 E / $9315824 \mathrm{~N})$, associado aos hornblenda monzogranitos, e apresenta altos teores de $\mathrm{Zr}$ (505 ppm), relativa abundância modal de cristais de zircão $(0,2 \%)$ e a ausência de forte recristalização dinâmica.

Os cristais de zircão do Complexo Granítico Estrela apresentam coloração castanha, formas geralmente prismáticas e alongadas, podendo por vezes exibir moderado fraturamento. Localmente são observados alguns cristais de zircão apresentando crescimento geminado. Zoneamento oscilatório moderado a forte pode ser descrito em alguns cristais do zircão (Fig. 2). São comuns as feições de metamictização (opacidade, fraturamento, coloração leitosa etc.), as quais são muito provavelmente relacionadas a altas concentrações de urânio nos cristais de zircão. Todavia, para as análises, foram selecionados cristais relativamente menos afetados por estas transformações.

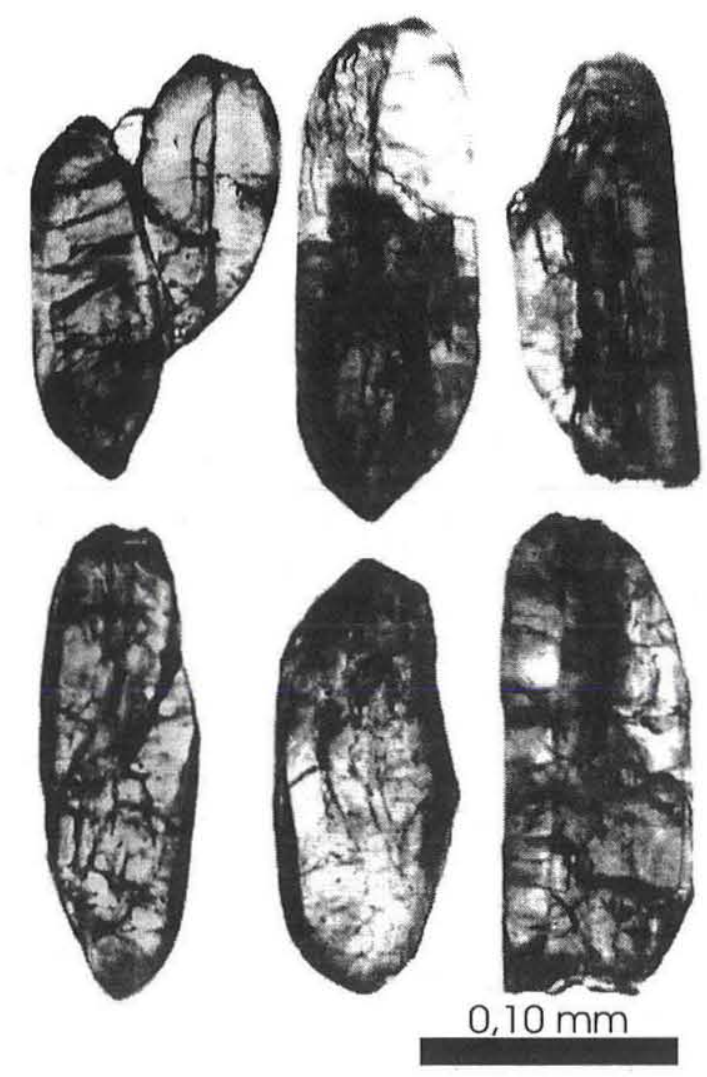

Figura 2- Fotomicrografia de cristais de zircão da amostra CRN8. Notar o zoneamento oscilatório de alguns cristais; localmente há cristais com crescimento geminado.
No método aplicado, cada cristal de zircão é colocado em um filamento de rênio e submetido à evaporação em diferentes temperaturas $\left(1450^{\circ} \mathrm{C}, 1500^{\circ} \mathrm{Ce} 1550^{\circ} \mathrm{C}\right)$, seguindo-se a técnica de Kober (1987). O Pb liberado pela evaporação é fixado no filamento de ionização. Durante o aquecimento deste filamento são analisadas, no espectrômetro, as intensidades das emissões dos diferentes isótopos de $\mathrm{Pb}$. A apresentação dos resultados considera os desvios a $2 \sigma$, e as correções do $\mathrm{Pb}$ comum são efetuadas com base no modelo de evolução do $\mathrm{Pb}$ em estágio duplo (Stacey \& Kramers 1975).

RESULTADOS ANALÍTICOS Os dados analíticos são apresentados na Tabela 2. Dos dez cristais selecionados, dois (cristais $4 \mathrm{e}$ 6) não apresentaram emissão de $\mathrm{Pb}$ suficiente para as análises. Dos restantes, os resultados de quartzo (cristais 1, 3, 7 e 10) foram eliminados do cálculo da idade média por apresentarem idade inferior à dos demais. Este comportamento certamente é produto da metamictização que afetou estes grãos, permitindo a perda de $\mathrm{Pb}$ radiogênico ao longo do tempo. Das três etapas de evaporação, os cristais de zircão analisados mostraram resultados preferencialmente nas etapas relativas às temperaturas de $1450^{\circ} \mathrm{C}$ e $1500^{\circ} \mathrm{C}$. Para os cristais de zircão 2 e 5 , que apresentaram diferentes resultados para essas duas etapas, apenas o de mais alta temperatura foi aproveitado para o cálculo da idade. A idade média calculada para os quatro cristais de zircão restantes (2, 5, 8 e 9) do Complexo Granítico Estrela é de $2763 \pm 7 \mathrm{Ma}(2 \sigma)$, a qual é considerada como a idade de cristalização dos cristais de zircão da amostra selecionada e de colocação do maciço.

Geocronologia Sm-Nd CONDIÇÕESANALÍTICAS As rochas analisadas são monzogranitos das fácies piroxênio-hornblenda (PSV-22), hornblenda (PSV-75), biotita-hornblenda monzogranito (PSV-62), hornblenda-biotita (CN-40) e biotita monzogranito (PSV77). Estas rochas são representativas da variação faciológica e geoquímica existente no Complexo Granítico Estrela. As três primeiras amostras pertencem ao grupo metaluminoso $\left(\mathrm{Al}_{2} \mathrm{O}_{3} \sim 11,5 \%\right)$ e as duas últimas amostras se enquadram no grupo de rochas fracamente peraluminosas $\left(\mathrm{Al}_{2} \mathrm{O}_{3} \sim 13,5 \%\right.$ ) (Barros et al. 1997).

As amostras, previamente pulverizadas, foram levadas à abertura por via úmida com $\mathrm{HF}_{\mathrm{FNO}} \mathrm{HNO}_{3} \mathrm{em}$ forno de microondas. Em seguida, foi realizada a separação química em duas etapas, utilizando-se colunas de cromatografia de troca iônica. Na primeira coluna é feita a separação dos elementos terras raras dos demais elementos maiores. Na segunda coluna é feita a separação de $\mathrm{Sm}$ e Nd dos elementos terras raras. A análise é realizada por espectrometria de massa, sendo que o depósito de Nd é feito em filamento de Ta e o de $\mathrm{Sm}$ em filamento de Re. Na análise química é empregado um arranjo de filamento duplo, constituído de um filamento de evaporação, onde é feito o depósito de $\mathrm{Sm}$ ou Nd, e um filamento de ionização. As razões isotópicas medidas do $\mathrm{Nd}$ são corrigidas para o fracionamento de massa utilizando como parâmetro de normalização a razão ${ }^{146} \mathrm{Nd} /{ }^{144} \mathrm{Nd}=0,7219$. Os cálculos das idades-modelo foram feitos com base na curva de evolução do manto empobrecido de DePaolo (1981).

As razões ${ }^{147} \mathrm{Sm} /{ }^{144} \mathrm{Nd}$ das amostras do Complexo Granítico Estrela variam de 0,10221 a 0,12729, com os valores algo mais baixos nas rochas com menor quantidade de anfibólio e biotita e algo mais altos em algumas amostras com maior quantidade daqueles minerais. Das cinco amostras analisadas, duas (PSV-62 e PSV-75) apresentaram razões ${ }^{147} \mathrm{Sm} /{ }^{144} \mathrm{Nd}$ em torno de 0,127 , as quais, segundo Sato \& Tassinari (1997), estão um pouco acima do limite 
Tabela 2 - Dados isotópicos de Pb de cristais de zircão - Complexo Granítico Estrela.

\begin{tabular}{ccccccc}
\hline Zircão & $\begin{array}{c}\text { Temperatura de } \\
\text { Evaporação }{ }^{\circ} \mathrm{C}\end{array}$ & $\begin{array}{c}\mathrm{N}^{\circ} \mathrm{de} \\
\mathrm{Razões}\end{array}$ & ${ }^{2044} \mathrm{~Pb}{ }^{296} \mathrm{~Pb} \pm 2 \sigma$ & ${ }^{2017} \mathrm{~Pb} / /^{2016} \mathrm{~Pb} \pm 2 \sigma$ & $\left({ }^{207} \mathrm{~Pb} /{ }^{2016} \mathrm{~Pb}\right) \mathrm{c} \pm 2 \sigma$ & Idade $(\mathrm{Ma}) \pm 2 \sigma$ \\
\hline CRN-8/2 & 1500 & 90 & $0.000000 \pm 0$ & $0.19187 \pm 25$ & $0.19187 \pm 25$ & $2759 \pm 2$ \\
CRN-8/5 & 1500 & 80 & $0.000003 \pm 2$ & $0.19171 \pm 33$ & $0.19169 \pm 34$ & $2757 \pm 3$ \\
CRN-8/8 & 1450 & 82 & $0.000000 \pm 0$ & $0.19403 \pm 57$ & $0.19403 \pm 57$ & $2777 \pm 5$ \\
& 1500 & 82 & $0.000002 \pm 1$ & $0.19333 \pm 27$ & $0.19332 \pm 27$ & $2771 \pm 2$ \\
& 1550 & 52 & $0.000000 \pm 0$ & $0.19397 \pm 44$ & $0.19397 \pm 44$ & $2776 \pm 4$ \\
CRN-8/9 & 1450 & 52 & $0.000002 \pm 2$ & $0.19138 \pm 49$ & $0.19134 \pm 49$ & $2754 \pm 4$ \\
& 1500 & 90 & $0.000000 \pm 0$ & $0.19101 \pm 35$ & $0.19101 \pm 35$ & $2751 \pm 3$ \\
& & 528 & & & & \\
\hline
\end{tabular}

Tabela 3- Dados analíticos Sm-Nd do Complexo Granítico Estrela.

\begin{tabular}{cccccccccc}
\hline Amostra & $\mathrm{Sm}$ & $\mathrm{Nd}$ & ${ }^{147} \mathrm{Sm} /{ }^{144} \mathrm{Nd}$ & $2 \sigma$ & ${ }^{143} \mathrm{Nd} /{ }^{144} \mathrm{Nd}$ & $2 \sigma$ & $\varepsilon_{\text {Nd(0) }}$ & $\mathrm{T}_{(\mathrm{DM})}$ & $\varepsilon_{\text {Nd(1) }}$ \\
\hline PSV-22 & 14.72 & 87.05 & 0.10221 & 0,00021 & 0.510853 & 0,000006 & -34.82 & 3.03 & -1.22 \\
CN-40 & 11.67 & 67.97 & 0.10378 & 0,00054 & 0.510892 & 0,000032 & -34.06 & 3.02 & -1.02 \\
PSV-77 & 5.85 & 33.67 & 0.10503 & 0.00042 & 0.510947 & 0.000016 & -32.99 & 2.97 & -0.38 \\
PSV-62 & 16.17 & 76.89 & 0.12716 & 0,00048 & 0.511265 & 0,000027 & -26.78 & 3.19 & -2.06 \\
PSV-75 & 16.04 & 76.20 & 0.12729 & 0.00144 & 0.511304 & 0.000036 & -26.02 & 3.12 & -1.34 \\
\hline
\end{tabular}

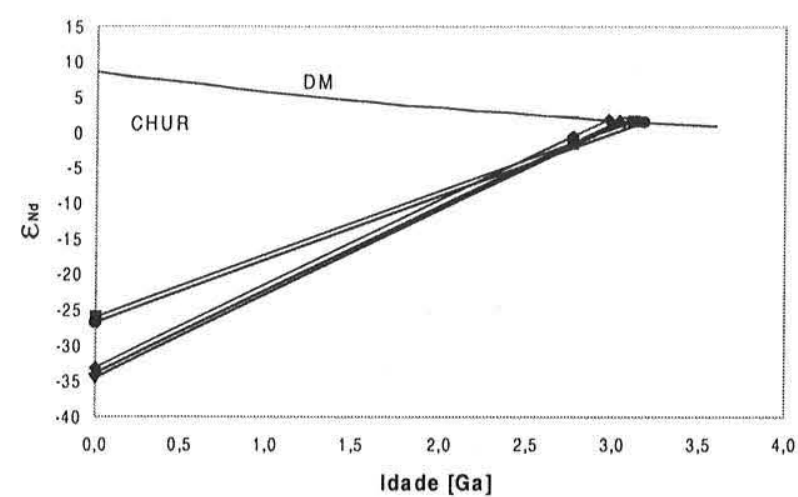

Figura 3-Diagrama Idade $(\mathrm{Ga})$ vs. $\varepsilon_{(\mathrm{Nd})}$ com dados do Complexo Granítico Estrela.

superior de 0,125 desejado para rochas félsicas. Como as razões ${ }^{147} \mathrm{Sm} /{ }^{144} \mathrm{Nd}$ destas amostras não são excessivamente elevadas e as idades-modelo não são discrepantes, preferiu-se mantê-las no conjunto de dados. Os valores de $\varepsilon_{\mathrm{Nd}(t)}$ se situam entre - 0,38 e $-2,06$ Ga e as idades-modelo $\left(\mathrm{T}_{\mathrm{DM}}\right)$ se situam entre 2,97 e 3,19 Ga (Tabela 3 e Fig. 3).

DISCUSSÃOECONCLUSÕES Implicações petrológicas Dois modelos petrogenéticos tentam explicar a origem de magmas graníticos do tipo A: 1) extremo fracionamento de magmas basálticos (Turner et al. 1992, Whalen et al. 1996), e 2) fusão parcial de rochas crustais de composição tonalítica ou granodiorítica (Anderson \& Bender 1989, Patiño-Douce 1997) ou de rochas metaígneas previamente granulitizadas (Skjerlie \& Johnston 1993, Landenberger \& Collins 1996).

A proximidade das idades das rochas máficas (Supergrupo Itacaiúnas) e ultramáficas (Complexo Luanga) (Machado et al. 1991) com a idade obtida para o Complexo Granítico Estrela, bem como os baixos valores da razão inicial ${ }^{87} \mathrm{Sr} /{ }^{86} \mathrm{Sr}(0,7018 \pm 0,00197)$, poderiam sugerir uma origem dos magmas graníticos a partir do extremo fracionamento de líquidos basálticos. Deve ser ressaltado que esta razão inicial foi obtida a partir de uma isócrona $\mathrm{Rb}-\mathrm{Sr}$ que forneceu uma idade de $2527 \pm 34 \mathrm{Ma}$ (Barros et al. 1992). Com a obtenção da idade de cristalização (Pb-Pb em zircão) de $2763 \pm 7$ Ma, a razão inicial poderia ser recalculada para esta idade. Porém, a confiabilidade desta razão inicial recalculada seria questionável em função de não se conhecer o deslocamento sofrido pela isócrona. De qualquer modo, mesmo supondo-se ter havido mudanças do valor da razão inicial ${ }^{87} \mathrm{Sr} /{ }^{86} \mathrm{Sr}$, admite-se, para efeito das considerações petrogenéticas, baixas razões iniciais.

Por outro lado, a ausência de encraves (autólitos) máficos, as idades $\mathrm{T}_{(\mathrm{DM})}(2,97 \mathrm{Ga}$ a $3,19 \mathrm{Ga})$ e os valores negativos $\varepsilon_{\mathrm{Nd}(\mathrm{t})}(-0,38$ a -2,06) são indicadores de uma fonte crustal. A geração dos magmas Estrela, de natureza alcalina e metaluminosa (Tipo-A), parece se ajustar melhor aos processos de fusão parcial de metatonalitos, de modo semelhante ao proposto por Anderson \& Bender (1989) e Patiño-Douce (1997). Este modelo torna-se mais adequado à razão inicial ${ }^{87} \mathrm{Sr} /{ }^{86} \mathrm{Sr}$ quando se considera uma fonte de natureza granulítica, onde se espera um empobrecimento em potássio e rubídio e, por conseqüência, menores razões iniciais ${ }^{87} \mathrm{Sr} /{ }^{86} \mathrm{Sr}$. O modelo petrogenético para estes granitóides envolvendo fontes crustais anidras explicaria as altas temperaturas necessárias para a fusão crustal e as altas temperaturas esperadas em magmas graníticos do tipo A, cujas concentrações de $\mathrm{Zr}$ são em geral elevadas. Estas temperaturas altas se traduzem, na área do Complexo Granítico Estrela, pela presença de rochas encaixantes submetidas a condições de fácies clinopiroxênio hornfels (Barros et al. 2001).

Na região de Carajás, fontes potenciais para as rochas do Complexo Granítico Estrela poderiam ser representadas por granulitos enderbíticos (hiperstênio tonalitos) descritos por Pidgeon et al. (2000), os quais apresentam idades de cristalização de 3,0 Ga e de granulitização de 2,85 Ga. Idades-modelo $\left(\mathrm{T}_{\mathrm{DM}}\right)$ de algumas rochas granitóides da região de Rio Maria (Rämo et al. 2002), situada mais a sul, têm valores semelhantes aos apresentados neste trabalho. Segundo Macambira \& Lafon (1995), a formação de parte da crosta mais antiga na região de Carajás poderia ter ocorrido póximo a 3,0 Ga. A granulitização de rochas crustais antigas poderia alternativamente ter ocorrido durante a colocação das sequiências vul- 
cânicas máficas do Supergrupo Itacaiúnas, pouco tempo antes da colocação do Complexo Granítico Estrela.

De acordo com Sylvester (1989), magmas graníticos do tipo A colocados em ambientes compressivos são preferencialmente derivados de fontes crustais, ao passo que, em ambientes distensivos, fontes mantélicas são mais favoráveis. Neste sentido, a hipótese de uma fonte crustal parece se adequar melhor aos dados isotópicos e ao modelo de colocação sintectônica, concomitante a esforços compressivos que atuaram na Província Mineral de Carajás há 2,76-2,74 Ga.

King et al. (1997) mostram que granitos metaluminosos do tipo A presentes no Cinturão Lachlan (Austrália) coexistem com granitos fracionados do tipo I, ambos colocados concomitantemente a esforços regionais. Segundo aqueles autores, a origem dos granitos metaluminosos do tipo A difere daquela dos granitos do tipo-I pelo fato de os primeiros terem sido gerados em condições de menor disponibilidade de $\mathrm{H}_{2} \mathrm{O}$ e menor fugacidade de oxigênio durante a fusão parcial que, em conseqüência, resultaria em magmas mais quentes. Estas diferenças nas condições de geração dos magmas do tipo I e metaluminosos do tipo A traduziram heterogeneidades nas fontes envolvidas. O Complexo Granítico Estrela encontra fortes semelhanças geoquímicas e estruturais com os granitos do tipo A descritos por King et al. (1997) e, como sugerido por aqueles autores, a expressão "tipo A" não deveria ser utilizada para denotar a colocação em condições anorogênicas e sim ressaltar a tendência alcalina destas rochas.

Implicações tectônicas Quando da obtenção da idade Rb-Sr em rocha total do Complexo Granítico Estrela, não se tinha um claro entendimento sobre a relação temporal entre a colocação do maciço e a sua deformação. Esta idade foi então interpretada como uma idade mínima, possivelmente relacionada com os processos deformacionais (Barros et al. 1992).

Mais tarde, trabalhos detalhados possibilitaram uma visão mais clara sobre a história de colocação do complexo granítico e seus efeitos metamórfico-estruturais sobre suas rochas encaixantes. Naquela ocasião, Barros et al. (2001) estabeleceram a natureza sintectônica do Complexo Granítico Estrela com base nos seguintes critérios estruturais, propostos por Gapais (1989), Gower (1993), Miller \& Paterson (1994), entre outros: a forma alongada do corpo, concordante com as estruturas de escala regional; a história de deformação progressiva em regime de temperatura decrescente; 0 paralelismo e transição de tramas magmáticas (estágio não completamente consolidado) para xistosidades formadas no estado sólido; o paralelismo das foliações presentes no granito e nas rochas encaixantes; padrão concêntrico de foliações primárias com deformação mais intensa nas bordas do que no centro do corpo granítico, e que indicam mecanismos de colocação por inchamento; padrão dômico marcado por acamamentos ígneos subverticais em periferia e subhorizontais no centro dos plútons; a presença de porfiroblastos sintectônicos em rochas encaixantes da auréola interna; e, finalmente, a coexistência de veios pegmatóides cogenéticos, sendo que aqueles precoces são muito foliados e dobrados, e aqueles relativamente tardios são pouco deformados.

A área estudada apresenta algumas semelhanças com domínios dos depósitos Salobo e Pojuca, situados a $50 \mathrm{~km}$ a oeste do Complexo Granítico Estrela, onde também foram descritos efeitos de contato em rochas metabásicas, provocados pelo Granito Old Salobo, considerado por Lindenmayer et al. (1994) como sintectônico. Com este quadro, Barros et al. (1997) sugeriram que o Complexo Granítico Estrela e os granitos Old Salobo e do Rio
Itacaiúnas, ambos com $2,55 \mathrm{Ga}$, fossem cronocorrelatos. Esta correlação é revista a partir dos novos dados geocronológicos $\mathrm{Pb}-\mathrm{Pb}$ apresentados neste trabalho.

A idade de $2763 \pm 7$ Ma marca uma fase de deformação compressiva que atuou na história arqueana da Província Mineral de Carajás após o desenvolvimento da Bacia Carajás. Outros granitos cronocorrelatos, como os pertencentes à Suíte Plaquê (Macambira et al. 1996), ao Granito Serra do Rabo (Sardinha et al. 2001) e ao Granito Planalto (Huhn et al. 1999), reforçam a importância deste magmatismo sintectônico como uma considerável fonte termal, responsável por modificações tectono-metamórficas verificadas nas séries metavulcano-sedimentares encaixantes, pertencentes ao Supergrupo Itacaiúnas (Barros et al. 2001).

Os efeitos de metamorfismo de contato em rochas metavulcanosedimentares provocados pelo Complexo Granítico Estrela comprovam que este é mais novo que as rochas supracrustais. Cálculos geobarométricos indicam que o Complexo Granítico Estrela foi colocado a pressões entre 2,5 e 3,5 kbar, ou seja, algo em torno de 10 quilômetros de profundidade (Barros et al. 2001). Em conclusão, pode-se dizer que após a instalação e preenchimento da bacia Carajás ocorreu uma fase de limitada compressão horizontal, acompanhada da colocação de granitos sintectônicos de nível crustal raso, os quais teriam promovido uma fase de metamorfismo de alta temperatura e baixa pressão com a formação de auréolas tectonotermais.

A idade de $2763 \pm 7$ Ma para este magmatismo granítico sintectônico corrobora a proposta de Pinheiro \& Holdsworth (1997), os quais sugerem que, entre 2,8 e 2,7 Ga, a região de Carajás foi submetida a uma fase compressiva. A fase de magmatismo, metamorfismo e deformação parece também se refletir nas idades de $2,7 \mathrm{Ga}$, obtidas pelo método ${ }^{40} \mathrm{Ar}^{39} \mathrm{Ar}$ em anfibólios de granulitos do Complexo Pium (Renne et al. 1988).

Os dados isotópicos apresentados neste trabalho, juntamente com idades de outras unidades (Machado et al. 1991; Pidgeon et al. 2000), permitem dizer que as rochas supracrustais da Bacia Carajás foram depositadas sobre uma crosta de natureza continental. A natureza toleítica dos basaltos, o hidrotermalismo regional destas rochas, indicativo de metamorfismo oceânico, e a presença de formações ferríferas associadas (Barros 1997) poderiam sugerir que a bacia atingiu um estágio de proto-oceano. Uma hipótese seria a deposição das rochas vulcânicas e das formações ferríferas em uma bacia pericontinental. Este ambiente parece explicar o empilhamento estratigráfico com rochas continentais servindo como o embasamento para derrames de basaltos em ambiente submarinho e durante esforços distensivos. O magmatismo granítico sintectônico a esforços compressivos, posterior à instalação da bacia, traduz esforços de encurtamento subhorizontal que poderiam refletir uma fase de subducção e subseqüente colisão de fragmentos crustais continentais. Entretanto, evidências inequívocas da presença de um arco magmático e de um episódio de subducção ainda não foram demonstradas na região de Carajás, ou porque a tectônica vertical foi predominante, ou porque este arco magmático se situa lateralmente, em áreas com menos estudos de detalhe.

Agradecimentos Este trabalho foi realizado com recursos do PROINT-UFPA (1998-2000) e do CNPq no âmbito do Programa Norte de Pós-Graduação (n 40003899), do Edital Universal (476623/ 01-4). As etapas de preparação das amostras, de coleta, seleção e análise dos cristais de zircão, e a captação de imagens, não teriam sido possíveis sem a imensa orientação da geóloga Cléris R. 
Sachett, do Prof. Cândido A. V. Moura e das estagiárias Vanderlucy P. de Melo e Elizety S. Leite. Somos muito gratos aos colegas Marco A. Galarza e Roberta Florencio pela realização das análises
Sm-Nd. Os autores agradecem os valiosos comentários e sugestões feitos pelos revisores. Este artigo é uma contribuição ao PRONEX-CNPq-FADESP(662103/1998-0, nº 420.00/00).

\section{Referências}

Anderson J.L. \& Bender B. 1989. Nature and origin of Proterozoic Atype granitic magmatism in the southwestern United States of America. Lithos. 23:19-52

Avelar V.0. 1996. Geocronologia Pb-Pb por evaporação em monocristal de zircão do magmatiwsmo da região de Tucumã, SE do Estado do Pará, Amozônia oriental. Dissertação de Mestrado, Universidade Federal do Pará, 149p

Barros C.E.M. 1997. Pétrologie et structure du Complexe Granitique Estrela $(2.5 \mathrm{Ga})$ et de son encaissant métavolcano-sédimentaire (Province Métallifère de Carajás, Brésil). Tese de Doutorado, Université Henri Poincaré - Nancy 1,316 p.

Barros C.E.M., Barbey P. \& Boullier A.M. 2001. Role of magma pressure, tectonic stress and crystallization progress in the emplacement of the syntectonic A-type Estrela Granite Complex (Carajás Mineral Province, Brazil). Tectonophysics, 343:93-109.

Barros C.E.M., Dall'Agnol R., Barbey P. \& Boullier A.M. 1997. Geochemistry of the Estrela Granite Complex, Carajás Region, Brazil: an example of an Archaean A-type granitoid. J. South-Amer: Earth Sci., 10(3-4):321-330.

Barros C.E.M., Dall'Agnol R., Lafon J.M., Teixeira N.P. \& Ribeiro J.W. 1992. Geologia e geocronologia Rb-Sr do Gnaisse Estrela, Curionópolis, PA. Bol. Mus. Par: Em. Goeldi, Ciênc. da Terra, 4:83102.

Bloem E.J.M., Dalstra H.J., Ridley J.R. \& Groves D.I. 1991. Granitoid emplacement during protracted tectonism in an Archaean granitoidgreenstone belt, Yilgarn Block, Western Australia. Precambrian Res., 85: $147-171$

Costa J.B.S., Teixeira N.P., Pinheiro R.V.L. \& Bermerguy R.L. 1990. Os sistemas estruturais transcorrentes do Cinturão Itacaiúnas na Região de Curionópolis, Leste do Estado do Pará. In: SBG, Congr. Bras. Geol., 35, Natal, Anais, 5:2345-2352.

Dall'Agnol R., Souza Z.S., Althoff F.J., Barros C.E.M., Leite A.A.S. \& Jorge João X.S. 1997. General aspects of the granitogenesis of the Carajás Metalogenic Province. In: CBPM, ISGAM, 2, Salvador, Excursion guide, 135-142.

Delor C., Burg J.P. \& Clarke G. 1991. Relations DiapirismMétamorphisme dans la Province du Pilbara (Australia occidentale): implications pour les régimes thermiques à l'Archéen. Comptes Rendues de l'Académie de Science de Paris,312:257-263.

DePaolo, D.J. 1981. Nd isotopic studies: Some new perspectives on Earth Structure and Evolution. EOS, 137-145.

Docegeo (Rio Doce Geologia e Mineração). 1988. Revisão litoestratigráfica da Província Mineral de Carajás. In: CVRD/SBG, Congr. Bras. Geol., 35. Belém, Província Mineral de Carajás - Litoestratigrafia e principais depósitos minerais. Anexo aos anais, pp.: 11-59.
Gapais D. 1989. Shear structures within deformed granites: mechanical and thermal indicators. Geology, 17:1144-1147.

Gower C.F. 1993. Syntectonic minor intrusions or synemplacement deformation? Can. J. Earth Sci., 30:1674-1675.

Huhn S.B., Macambira M.J.B. \& Dall'Agnol R. 1999. Geologia e Geocronologia $\mathrm{Pb}-\mathrm{Pb}$ do Granito Alcalino Arqueano Planalto, Região da Serra do Rabo, Carajás - PA. In: SBG, Simp. Geol. Amaz., 6, Manaus, Anais, 1:463-466.

Jelsma H.A., Van der Beek P.R. \& Vinyu M.L. 1993. Tectonic evolution of the Bindura-Shamva greenstone belt (northern Zimbabwe): Progressive deformation around diapiric structures. J. Struct. Geol., 15:163-176.

King P.L., White A.J.R., Chappel B.W. \& Allen C.M. 1997. Characterization and Origin of Aluminous A-type Granites from the Lachlan Fold Belt, Southeastern Australia. J. Petrol., 30(3):371391.

Kober B. 1987. Single grain evaporation combined with $\mathrm{Pb}$ emitter bedding ${ }^{207} \mathrm{~Pb} /{ }^{206} \mathrm{~Pb}$ investigations using thermal ion mass spectrometry and implications to zirconology. Contrib. Mineral. Petrol., 96:6371 .

Landenberger B. \& Collins W.J. 1996. Derivation of A-type Granites from a Dehydrated Charnockitic Lower Crust: Evidence from a Chaelundi Complex, Eastern Australia. J. Petrol., 37(1):145-170.

Lindenmayer Z.G. \& Fyfe W. S. 1991. Metamorfismo de alta temperatura e baixa pressão no depósito de cobre do Salobo: evidência de rift continental arqueano no Cráton Amazônico. In: SBG, Simp.Geol. Amaz., 3, Belém, Anais, 36-48.

Lindenmayer Z.G., Fyfe W.S. \& Bocalon V.L.S. 1994. Nota Preliminar sobre as Intrusões Granitóides do Déposito de Cobre do Salobo, Carajás. Acta Geol .Leopold., 40(XVII):153-184.

Macambira E.M.B., Jorge-João X.S., Souza E.C. 1996. Geologic and petrologic aspects of the Plaquê Granite, Southeastem of Pará State. In: SBG, Symp. Archean Terranes South Amer. Platform, Brasília, Extended abstracts, pp. 73-75

Macambira M.J.B. \& Lafon J.M. 1995. Geocronologia da Província Mineral de Carajás: síntese dos dados e novos desafios. Bol. Mus. Par. Emílio Goeldi, Ciênc. da Terra, 7:263-288.

Macambira M.J.B., Silva, D.C.C., Scheller T. \& Barros C.E.M. 2003. New isotope evidences confirming the existence of a Paleoproterozoic terrain in the region at the north of the Carajas Mineral Province. In: Simp.Sul-Amer. Geol. Isotópica, 4, Salvador, CD-ROM.

Machado N., Lindenmayer Z., Krogh T.H. \& Lindenmayer Z.G. 1991. $\mathrm{U}-\mathrm{Pb}$ geochronology of Archaean magmatism and basement reactivation in the Carajás area, Amazon shield, Brazil. Precambrian Res.49:329-354.

Miller R.B. \& Paterson S.R. 1994. The transition from magmatic to hightemperature solid-state deformation implications from the Mount 
Stuart Batholith, Washington. J. Struct. Geol., 16:853-865.

Mougeot R., Respaut J.P., Ledru P., Milesi J.P., Macambira M.J.B. \& Huhn S.B. 1996. Contrainte géochronologique U-Pb pour l'âge de la formation sédimentaire de Águas Claras (Province de Carajás, Etat de Pará.). In: BRGM, Réunion des Sciences de la Terre, 16, Orléans, 67.

Nogueira A.C.R., Truckenbrodt W. \& Pinheiro R.V.L. 1995. Formação Águas Claras, Pré-Cambriano da Serra dos Carajás: redescrição e redefinição litoestratigráfica. Bol. Mus. Par. Em. Goeldi, Ciênc. da Terra, 7:177-277.

Patiño-Douce, A.E. 1997. Generation of metaluminous A-type granites by low-pressure melting of calc-alkaline granitoids. Geology, 25:743746.

Pidgeon R.T.; Macambira M.J.B. \& Lafon J.M. 2000. Th-U-Pb isotopic systems and internal structures of complex zircons from an enderbite from the Pium Complex, Carajás Province, Brazil: evidence for the ages of granulites facies metamorphism and the protolith of the enderbite. Chem. Geol., 166:159-171.

Pinheiro R.V.L. \& Holdsworth R.E. 1997. Reactivation of Archaean strikeslip fault systems, Amazon region, Brazil. J. Geol. Soc.London, 154:99-103.

Rämo T., Dall'Agnol R., Macambira M.J.B., Leite, A.A.S., Oliveira, D.C. 2002. 1.88 Ga Oxidized A-type Granites of the Rio Maria, Eastern Amazonian Craton, Brazil: Positively Anorogenic! J. Geol., 110:603-611.

Renne P.R., Onstott T. \& Jorge João X.S. 1988. ${ }^{40} \mathrm{Ar} /{ }^{39} \mathrm{Ar}$ and paleomagnetic results from the Guaporé Shield: further implications for the nature of Middle-Late Proterozoic mobile belts of Gondwanaland. In: SBG, Congr. Lat.-Amer. Geol., 7, Belém, 1:348362 .

Sardinha A.S., Barros C.E.M., Krimsky R. \& Macambira M.J.B. 2001. Petrografia e Geocronologia U-Pb em zircão do Granito Serra do Rabo, Província Mineral de Carajás, Pará. In: SBG, Simp. Geol.
Amaz., 7, Belém, CD-ROM.

Sato K. \& Tassinari C.G.G. 1997. Principais eventos de acreção continental no Cráton Amazônico baseados em idade-modelo Sm-Nd, calculada em evoluções de estágio único e estágio duplo. In M.L. Costa \& R.S. Angélica (eds.). Contribuições à Geologia da Amazônia. Belém, FINEP/SBG-NO, 91-142.

Skjerlie, K.P. \& Johnston A.D. 1993. Fluid-Absent Melting Behavior of an F-Rich Tonalitic Gneiss at Mid-Crustal Pressures: Implications for the Generation of Anorogenic Granites. J. Petrol., 34: 785-815.

Souza S.R.B., Macambira M.J.B. \& Sheller T. 1996. Novos dados geocronológicos para os granitos deformados do Rio Itacaiúnas (Serra dos Carajás, PA); implicações estratigráficas. In: SBG, Simp. Geol. Amaz., 5, Belém, 380-383.

Sylvester P.J. 1989. Post-collisional alkaline granites. J. Geol., 97:261280.

Stacey J.S. \& Kramers J.D. 1975. Approximation of terrestrial lead isotope evolution by a two stage model. Earth Planet. Sci. Lett., 26:207221.

Turner S.P., Foden J.D. \& Morrison R.S. 1992. Derivation of some Atype magmas by fractionation of basaltic magma: An example from the Padthaway Ridge, South Australia. Lithos, 28:151-179.

Whalen J.B., Currie K.L. \& Chappell B.W. 1987. A-type granites: geochemical characteristics, discrimination and petrogenesis. Contrib. Mineral. Petrol., 95:407-419.

Whalen J.B., Jenner G.A., Longstaffe F., Robert F. \& Gariépy C. 1996. Geochemical and Isotopic $(\mathrm{O}, \mathrm{Nd}, \mathrm{Pb}$ and $\mathrm{Sr})$ Constraints on $\mathrm{A}$ type Granite Petrogenesis Based on the Topsails Igneous Suite, Newfoundland Appalachians. J. Petrol., 37:1463-1489.

Manuscrito A-1434

Recebido em 20 de maio de 2003

Revisão dos autores em 15 de junho de 2004 Revisão aceita em 30 de julho de 2004 